In this article, the authors propose a non-invasive method to evaluate children with enuresis by correlating findings of color Doppler ultrasound of ureteric jet and bladder wall thickness. The authors compared the ultrasound findings in a group of 203 children with a "natural filling cystometry" method, and found a positive statistical correlation between bilateral monophasic jets and abnormal urodynamic findings.

Although "natural filling cystometry" is not used in clinical practice worldwide, this study is of interest due to its non-invasive and relatively simple technical nature. There are, however, limitations recognized by the authors:

- The study is time consuming. Children must wait up to one hour after hydration, until their bladder is very full, before the ultrasound study can be performed. The ultrasound examination itself takes only 15 minutes.

- The training needed takes several weeks before proficiency in the performance of the studies is achieved. There was no report of inter-observer variability in this study, which is an important variable.

Enuresis is a common problem and a non-invasive evaluation method is desirable. Evaluation of this proposed method in a clinical setting, and validation by other investigators, would establish this as a new application of ultrasonography and Doppler in children.

M. Ines Boechat, M.D.

Director and Chief of Pediatric Imaging

Department of Radiology

David Geffen School of Medicine

University of California, Los Angeles

\title{
Ureteric Jet Doppler Waveform and Bladder Wall Thickness in Children With Nocturnal Enuresis
}

\author{
VIVIAN YEE-FONG LEUNG, WINNIE CHIU-WING CHU, CHUNG-KWONG YEUNG, AND CON METREWELI
}

Department of Diagnostic Radiology and Organ Imaging [V.Y.-F.L., W.C.-W.C., C.M.], Department of Surgery [C.-K.Y.], Prince of Wales Hospital, The Chinese University of Hong Kong, Hong Kong SAR, China

\begin{abstract}
To test the hypothesis that the presence of nocturnal enuresis is related to increased frequency of immature vesicoureteric function, which is further associated with detrusor overactivity, we compared the incidence of immature monophasic ureteric jet in children with and without nocturnal enuresis. The relationship between monophasic ureteric jet Doppler wave form and bladder wall thickness was further explored in the enuresis group. Ultrasound examinations were performed in 511 children suffering from nocturnal enuresis and 266 normal controls. Doppler wave forms of the ureteric jet on each side and the bladder wall thickness after voiding were recorded. Standard urodynamic studies were obtained in 203 enuretic children for correlations with ultrasound findings. There was a significant increase in the incidence of monophasic ureteric jet waveforms in enuretic children when compared with the controls ( $19.2 \%$ versus $6.4 \%$ on the right side, $19.2 \%$ versus $8.3 \%$ on the left
\end{abstract}

Received February 13, 2006; accepted June 20, 2006

Correspondence: Winnie Chiu-Wing Chu, Ph.D., Diagnostic Radiology and Organ Imaging Department, Prince of Wales Hospital, Chinese University of Hong Kong, Shatin, New Territories, Hong Kong SAR, China; e-mail: winnie@med.cuhk.edu.hk side, all $p<0.01$ ). Furthermore, immature monophasic waveforms were more commonly seen in the enuretic group with markedly thickened bladder wall. Enuretic children with bilateral immature ureteric jet waveforms and markedly thickened bladder wall showed multiple significant urodynamic abnormalities $(p<0.05)$. The above observations could be accounted for by immaturity of both vesicoureteric junction and detrusor muscle. (Pediatr Res 60: 582-586, 2006)

$\mathrm{E}^{\mathrm{n}}$ nuresis is a worldwide problem. In the western population, the incidence has been reported to be $15-20 \%$ in 5 -y-old and $10 \%$ in 7 - to 12 -y-old children (1). The prevalence in the Chinese population was reported to be $3.5 \%$ in $4-$ to 12-y-old children (2). Despite the lower incidence in China,

DOI: 10.1203/01.PDR.0000242304.64309.6c 
this clinical problem still imposes stress on the children and their families and constitutes a significant number of outpatient pediatric consultations in our locality.

The pathogenesis of enuresis is extremely controversial. Suggested etiologies have included psychological and behavioral disturbance (3), lack of arousal from sleep (4-7), overproduction of nocturnal urine (8-12), and delayed maturation of neural pathways and bladder abnormalities (6,13-16).

Despite the many advances in knowledge on this field that have been described in the literature (13,16-19), higher voiding detrusor pressure is a well-recognized feature of immaturity, which may be associated with bladder disturbances such as bladder over-activity (16-18). Furthermore, detrusor abnormalities may manifest as bladder wall thickening $(13,19)$.

In our previous studies, we have demonstrated that a bimodal active sphincteric mechanism is present in the human VUJ, which challenges the traditional belief of predominately passive role in the VUJ (20). Immature sphincteric action at the VUJ is manifested by the presence of a monophasic Doppler wave form of the ureteric jets. The monophasic wave form is universal from birth to 6 mo of age. It is commonly observed in children under $4 \mathrm{y}$ of age and present in older children who have UTI or VUR (21). The mature pattern shows a complex of two or more peaks $(20,21)$.

In this study, we sought to examine the ureteric jet Doppler wave form patterns in enuretic children and compared it with those of normal children to see whether an immature sphincteric action at the VUJ was more frequently found in children with enuresis. Furthermore, any association between immature ureteric jet and abnormal bladder wall thickness (as an index of detrusor abnormalities) was determined. Correlations were also made with urodynamic studies.

\section{SUBJECTS AND METHODS}

Subjects. All children $5 \mathrm{y}$ of age and older who were referred to the pediatric outpatient clinic in our center and presenting with primary nocturnal enuresis were prospectively recruited for the ultrasound examination. None of them had any neurologic deficit, spine surgery, or were on enuresis treatment. The parents of the children were interviewed according to a detailed clinical questionnaire on their first clinical visit. All recruited subjects had a history of bed-wetting four or more times per week for a duration of at least the past 6 mo. Subjects who had concurrent daytime incontinence were excluded from this study.

Normal controls, $5 \mathrm{y}$ of age and older, were recruited from the pediatric outpatient ultrasound session of the radiology department. These children were referred for ultrasound examinations for various reasons. Patients referred for urinary tract examination were excluded. Careful history was taken from the controls to exclude any current urinary symptoms or recent UTI. All normal subjects had good toilet control without history of either day-wetting or bed-wetting.

Informed consent was obtained from the parents of all subjects. The study was approved by the institutional review committee of the Chinese University of Hong Kong.

The study population included 511 children suffering from primary nocturnal enuresis and 266 normal controls.

Ultrasound examination. Before ultrasound scanning, all children were encouraged to drink a large volume of water, around $600 \mathrm{~mL}$ on average, or the maximum amount they could tolerate. Scanning started $20 \mathrm{~min}$ after the fluid loading or earlier if the child indicated urgent toilet needs. This ensured the subjects were well hydrated but were not under excessive diuretic stress (20). The total scanning time was about $15 \mathrm{~min}$, although some children needed to stay in the waiting area for a longer time to achieve a full bladder status. The average time to complete the whole examination was therefore around $1 \mathrm{~h}$ for each subject.
Ultrasound measurements and Doppler wave form assessment were performed using an ATL 5000 ultrasound unit (Advanced Technology Laboratories, Bothell, WA). A 3.5-or 5-MHz probe was used, depending on the size of the subjects. The pulse repetition frequency was $2.5 \mathrm{kHz}$ and was adjusted as needed until no aliasing occurred. A low wall filter was used. The sample volume was opened wide enough to include the entire jet and it was centered at the point of maximum flow. A slow sweep speed of $25 \mathrm{~mm} / \mathrm{s}$ of the Doppler wave form was set to cover the whole jet wave form. Color, Doppler scale, and gain were adjusted to avoid aliasing. Doppler angle was limited within $30-60^{\circ}$.

All subjects were studied in the supine position. The urinary bladder was scanned in the transverse plane. The interureteric bar was used as the landmark for the ureteric orifice. If the above structure was not readily identified, then the ureteric jets were located by identifying the color signal. Once the color signals of the jets were identified, both color and simultaneous Doppler waveforms of the jets from the orifice of each side were obtained alternately.

In each subject, three consecutive waveforms on either side of the ureteric jet were obtained for measurement. The number of peaks in each wave form was recorded. The wave form of the jet was classified according to the number of peaks within that particular wave. According to the observations in our previous studies (20), there were six basic patterns: 1) monophasic (only one peak), 2) biphasic (two peaks), 3) triphasic (three peaks), 4) polyphasic (number of peaks exceeded three), 5) "square" (a plateau wave form in which no distinct peak could be identified), and 6) "continuous" (when the wave form lasted longer than $20 \mathrm{~s}$ ). The last two patterns were associated with diuretic stress, which was deliberately avoided in this study.

In addition, the maximum bladder wall thickness was measured after voiding in all enuresis subjects. To ensure adequate voiding, bladder emptying efficiency needed to be $>90 \%$, with details as follows. Bladder volume was first measured when the child had the sensation of maximum fullness. It was then remeasured after voiding. The bladder emptying efficiency was calculated as follows: (prevoiding volume - post voiding volume)/prevoiding volume. If $>90 \%$ efficiency was not achieved, the subject would proceed with further voiding. Bladder wall thickness was only measured when the residual bladder volume was $<10 \%$ of original. The maximum wall thickness was calculated as the average of the maximal diameters measured at the anterior, lateral, and posterior walls of the urinary bladder. The maximum bladder wall thickness calculated was further divided into five grades arbitrarily based on the measurement data obtained in this study, as there was no detailed published reference on this aspect: grade I, bladder wall thickness smaller than mean -1 SD to mean -2 SD; group II, wall thickness smaller than mean -1 SD to mean; group III, wall thickness from mean to mean $+1 \mathrm{SD}$; group IV, wall thickness greater than mean $+1 \mathrm{SD}$ to mean $+2 \mathrm{SD}$; and group IV, wall thickness greater than mean +2 SD. According to Jequier's (22) study, an average bladder wall thickness up to $5 \mathrm{~mm}$ (i.e. up to grade III in this study) was considered normal. In this study, a grade IV wall thickness was considered as moderately thickened and a grade $\mathrm{V}$ wall thickness was considered as markedly thickened.

Urodynamic examination. Among the 511 enuretic children, 203 were randomly selected for urodynamic examination with both NFC and conventional filling cystometry.

The NFC results were used for correlation with ultrasound measurements because both methods involved natural filling of the urinary bladder.

The NFC was performed using an ambulatory urodynamic recorder with continuous online pressure display during bladder filling and emptying. The ambulatory urodynamic recorder consisted of a specially developed integral transmitter that converts digital pressure signals to modulated infrared waves. The signal emitted from the recorder was received by a receiver mounted on the ceiling of examination room, which was then transmitted to the computer in the room of the urodynamicist next door. During the urodynamic investigation, the children could conduct normal activities, be totally mobile, and be accompanied by parents undisturbed in a private cubicle. Further details of the equipment can be reviewed in our previously published study (23). Data gathered during the day were compared with the data obtained by the cystometric recordings at night. Detailed recording of day and night urinary output was also performed for each child. During the day, the subjects were instructed to void their urine into a specific measuring jar. At night, the subjects were required to wear diapers connected to a temperate sensor for bed-wetting indication. The net weight of the diaper was measured. All the measurements were carried out by a team of research fellows experienced in performing urodynamic studies. The following parameters were recorded:

1. Clinical presentation: number of bedwetting incidents per week and per night, daytime urgency, frequency, and urge incontinence 
2. Pattern of the bladder and sleeping pattern, including unstable contraction of the bladder, dyssynergia, and evidence of EMG activity of the pelvic floor muscle

3. Maximum detrusor pressure of the urinary bladder

4. Volume of the urinary bladder: the voided volume, residual volume, capacity, percentage of volume achieved, and emptying efficiency

5. Volume of voiding: number of voidings, day and night urine volume and their ratio (nocturnal polyuria), the mean, maximum and total volume of bedwetting at night, and the first morning urine volume

6. Day and night serum and urine osmolarity, and vasopressin concentration at 1400, 2000, 0000, 0400, and $0800 \mathrm{~h}$ were recorded.

Night-time urine output was measured as the total urine volume collected in the diaper (assessed by weighing the diaper in the morning) plus the first morning urine volume. Nocturnal polyuria was defined as a day:night urine volume ratio of $<1$ (7). The timing and characteristic of the urinary flow, the relationship with pressure changes, and activities during the study period were noted continuously by an observer. The recordings were acquired for a minimum of three voids or until a reproducible micturition pattern was obtained. The postmicturition residual urine volume was measured by emptying the bladder after the last void. Bladder emptying efficiency was calculated as the ratio of voided volume to capacity (voided volume + residual volume).

Statistical analysis. According to the results of our previous studies, monophasic jet wave form (pattern 1) was considered to be the immature pattern $(20,21)$. Children in this study were therefore divided into three groups: normal jet (pattern 2, 3, and 4), unilateral monophasic, and bilateral monophasic (pattern 1). As we have observed that jet patterns were not always identical on both sides and a small number of subjects only presented with unilateral monophasic jets (which was probably caused by developmental asynchrony), the results were further separately divided into right and left side.

$\chi^{2}$ test, independent sample $t$ test, Mann Whitney test, Wilcoxon signed rank test, and Spearman's rank correlation were used in the statistical analysis. A value of $p<0.05$ was considered statistically significant.

\section{RESULTS}

There were 266 normal children and 511 enuretic children undergoing ultrasound examination. For both groups, the age ranged from 5 to $18 \mathrm{y}$ old. The mean age was $10.68 \pm 3.95 \mathrm{y}$ in the normal group, with 132 boys and 134 girls. The mean age was $8.71 \pm 2.61 \mathrm{y}$ in the enuresis group with 368 boys and 143 girls.

Among the enuretic children, 203 underwent urodynamic study (mean age, $9.20 \pm 2.56 \mathrm{y}$, with 142 boys and 61 girls) whereas 308 did not (mean age, $8.53 \pm 2.61 \mathrm{y}$, with 226 boys and 82 girls). There was no significant difference between the age and severity of bed-wetting between the two groups.

Ureteric jet pattern. The distribution of jet pattern in both normal and enuretic groups is given in Table 1. No subjects had continuous pattern (pattern 6) and only $0.4 \%$ of the

Table 1. Distribution of the jet pattern in 266 normal and 511 enuretic children

\begin{tabular}{|c|c|c|c|c|c|c|c|c|}
\hline \multirow[b]{3}{*}{ Jet Pattern } & \multicolumn{4}{|c|}{ Normal } & \multicolumn{4}{|c|}{ Enuretic } \\
\hline & \multicolumn{2}{|c|}{ Right } & \multicolumn{2}{|c|}{ Left } & \multicolumn{2}{|c|}{ Right } & \multicolumn{2}{|c|}{ Left } \\
\hline & No. & $\%$ & No. & $\%$ & No. & $\%$ & No. & $\%$ \\
\hline Monophasic & 17 & 6.4 & 22 & 8.3 & 98 & 19.2 & 98 & 19.2 \\
\hline Biphasic & 87 & 32.7 & 85 & 31.9 & 136 & 26.6 & 161 & 31.5 \\
\hline Triphasic & 98 & 36.8 & 96 & 36.1 & 163 & 31.9 & 141 & 27.6 \\
\hline Polyphasic & 63 & 23.7 & 62 & 23.3 & 114 & 22.3 & 111 & 21.7 \\
\hline Square & 1 & 0.4 & 1 & 0.4 & 0 & 0 & 0 & 0 \\
\hline Continuous & 0 & 0 & 0 & 0 & 0 & 0 & 0 & 0 \\
\hline
\end{tabular}

normal controls had the square pattern (pattern 5). These could be explained by the lack of diuretic stress in the study population.

There was a much higher incidence of immature jet in the enuretic group when compared with the normal controls $(p<$ $0.01, \chi^{2}$ test). However, there was no significant difference in the incidence of immature jet between the right side and the left side in either the control group or the enuretic group $(p>$ 0.05 , Wilcoxon signed rank test).

Bladder wall thickness. All 511 enuretic children were included in the analysis. However, only 504 children could complete the bladder wall thickness measurement because some of them had complete collapse of the urinary bladder after micturition (i.e.100\% emptying efficiency) and therefore the bladder wall thickness could not be assessed satisfactorily. The mean average bladder thickness was $3.85 \pm 1.23 \mathrm{~mm}$. The bladder wall thickness was divided into five groups, as described in "Subjects and Methods." The results are given in Table 2.

Enuretic children with markedly thickened (grade V) bladder walls had the highest incidence of monophasic ureteric jet $(50 \%)$ when compared with the other groups (17\% in group I; $25 \%$ in group II; $23.8 \%$ in group III, and $23.5 \%$ in group IV).

Relationship with urodynamic results. The relationship of jet pattern with urodynamic measurements in 203 enuretic children is given in Table 3. Children with bilateral immature jet pattern showed significant correlations with higher detrusor pressure, smaller voided urine volume, and night urine volume. These children also had smaller bladder volume and achieved a smaller bladder volume than expected for their age when compared with the normal controls (all $p<0.05$, independent sample $t$ test).

The relationship of the bladder wall thickness with urodynamic measurement is given in Table 4. Bladder wall thickness showed significant positive correlations with high detrusor pressure, increased frequency of unstable bladder contraction, and dyssynergia whereas negative correlations were found between bladder wall thickness with voided volume, bladder volume achieved, and bladder capacity (all $p<$ 0.05 , Spearman's rank correlation).

\section{DISCUSSION}

Detrusor muscle overactivity and enuresis. The pathogenesis of enuresis is still unclear. Immaturity of the bladder function, especially the detrusor muscle, is one of the major areas to be reviewed.

Table 2. Bladder wall thickness in 504 enuretic children

\begin{tabular}{lcc}
\hline \multicolumn{1}{c}{ Grading } & $\begin{array}{c}\text { Bladder wall } \\
\text { thickness } \\
(\mathrm{mm})\end{array}$ & $\begin{array}{c}\text { No. of } \\
\text { children }(\%)\end{array}$ \\
\hline I $($ mean $-2 \mathrm{SD}<x<$ mean $-1 \mathrm{SD})$ & $1.39-2.62$ & $68(13.5)$ \\
II $($ mean $-1 \mathrm{SD}<x<$ mean $)$ & $2.62-3.85$ & $193(38.3)$ \\
III $($ mean $<x<$ mean $+1 \mathrm{SD})$ & $3.85-5.08$ & $164(32.5)$ \\
IV $($ mean $+1 \mathrm{SD}<x<$ mean $+2 \mathrm{SD})$ & $5.08-6.31$ & $51(10.1)$ \\
V $(x>$ mean $+2 \mathrm{SD})$ & $6.31-7.54$ & $28(5.6)$ \\
\hline
\end{tabular}

Mean $=3.85 \mathrm{~mm}, \mathrm{SD}=1.23 \mathrm{~mm}, x=$ bladder wall thickness. 
Table 3. Relationship between monophasic waveform and urodynamic measurement in 203 enuretic children

\begin{tabular}{|c|c|c|c|c|c|}
\hline Parameter & Mature jet, mean & \multicolumn{2}{|c|}{ Unilateral monophasic } & \multicolumn{2}{|c|}{ Bilateral monophasic } \\
\hline Detrusor pressure $\left(\mathrm{cm} \mathrm{H}_{2} \mathrm{O}\right)$ & 76.76 & 86.80 & 0.285 & 110.38 & 0.010 \\
\hline Bladder capacity $(\mathrm{mL})$ & 181.00 & 174.01 & 0.763 & 132.01 & 0.026 \\
\hline Bladder volume achieved (\%) & 53.29 & 55.65 & 0.707 & 41.97 & 0.044 \\
\hline Night urine volume $(\mathrm{mL})$ & 354.18 & 336.43 & 0.625 & 273.39 & 0.040 \\
\hline
\end{tabular}

Only parameters with significant relationship are shown. $p$ Value is compared with the mature jet, independent sample $t$ test. Values highlighted in bold: $p$ value $<0.05$.

Table 4. Correlation between bladder wall thickness and urodynamic measurement in 203 enuretic children

\begin{tabular}{lcc}
\hline & $p$ Value & $\begin{array}{c}\text { Correlation } \\
\text { coefficient }(R)\end{array}$ \\
\hline Detrusor pressure $\left(\mathrm{cm} \mathrm{H} \mathrm{H}_{2} \mathrm{O}\right)$ & 0.000 & 0.391 \\
Bladder capacity $(\mathrm{mL})$ & 0.009 & -0.204 \\
Bladder volume achieved $(\%)$ & 0.005 & -0.216 \\
Voided volume $(\mathrm{mL})$ & 0.007 & -0.207 \\
Unstable contraction & 0.000 & 0.303 \\
Dyssynergia & 0.006 & 0.210 \\
\hline
\end{tabular}

Only parameters with significant relationship ( $p$ value $<0.05$, Spearman's rank correlation) are shown.

In a normal subject, during the filling phase when the bladder volume increases, there should neither be any involuntary bladder contractions, nor any increase in detrusor pressure. The subject is considered to have a "stable" detrusor. If the detrusor muscle contracts during the filling phase, it is considered to be "overactive" $(7,19,24)$. The exception to the above rule is observed in infants. During infancy, detrusor contraction often occurs throughout the filling phase $(19,25)$. The detrusor muscle becomes stable when one grows; however, detrusor instability might occur in $10 \%$ of the general population and the incidence increases with age $(19,24)$.

There are two types of overactive detrusor. "Bladder overactivity of neurogenic origin" is caused by a relevant neurologic disorder. "Bladder overactivity" is caused by bladder outflow obstruction, detrusor muscle abnormality, and unrecognized underlying neurologic abnormality. Even a psychosomatic etiology has been suggested for the latter. Patients with detrusor overactivity have sensations of fullness at a lower bladder volume than normal $(19,24,26,27)$.

A number of studies have suggested presence of detrusor overactivity in enuretics $(7,13,28)$. Watanabe and Azuma (29) found enuretics had more unstable contractions at night than at daytime. In Cisternino and Passerini-Glazel's (30) study, detrusor overactivity was observed in subjects with nocturnal enuresis with daytime incontinence but not in those with primary nocturnal enuresis.

Detrusor muscle overactivity and bladder wall thickness. In long-standing detrusor overactivity, the bladder wall may become thicker, trabeculated, and irregular in contour $(13,19)$. Tibballs and De Bruyn (31) found that mean bladder wall thickness in normal boys was $0.306 \mathrm{~cm}$ and in normal girls was $0.273 \mathrm{~cm}$. There was no statistically significant difference sex. In this study, over half of the enuretic children had significantly thickened bladder wall $(>0.5 \mathrm{~cm})$. Bladder wall thickness could be one of the features of detrusor immaturity as suggested in previous studies $(13,19,31)$. This was further supported by the strong association found between thickened bladder wall with high detrusor pressure, unstable bladder contraction, and dyssynergia in this study.

Detrusor muscle overactivity and voiding detrusor pressure. The reported ranges of voiding detrusor pressure in urodynamic examinations were very variable in different studies. In general, normal voiding pressure in the bladder should not exceed $30 \mathrm{~cm}$ of water pressure $(32,33)$. However, the pressure is higher in boys (range, $15-131 \mathrm{~cm} \mathrm{H}_{2} \mathrm{O}$ ) than in girls $\left(10-87 \mathrm{~cm} \mathrm{H}_{2} \mathrm{O}\right)$. It is also higher in infants $(40-60 \mathrm{~cm}$ $\mathrm{H}_{2} \mathrm{O}$ ) than in adults. A high voiding pressure may indicate outlet obstruction or an overactive but otherwise healthy detrusor muscle $(16-18,25,34)$.

Based on the various findings from the above studies, higher voiding detrusor pressure is likely to be a feature of immaturity; which is associated with detrusor overactivity while detrusor abnormality might manifest itself as bladder wall thickening.

Monophasic ureteric jet wave form and enuresis. In previous studies, we have suggested that there is a bimodal active sphincteric mechanism in the human VUJ, and it is possible to identify an immature and mature wave form (20). Immature sphincteric action is manifested by the presence of a monophasic Doppler wave form. The mature pattern shows a complex of two or more peaks. The monophasic wave form is universal from birth to $6 \mathrm{mo}$ of age and is common in children under $4 \mathrm{y}$ of age. In older children, the monophasic jet pattern is increasingly found in those with abnormal VUJ function, namely VUR and UTI $(20,21)$.

In this study, children with nocturnal enuresis were found to have higher incidence of the immature wave form when compared with normal children of the same age range. This suggests that there is a lower level of maturity of the VUJ in a proportion of the enuretic children. The above hypothesis was supported by the association of more deranged urodynamic parameters in children with monophasic jet pattern.

Monophasic ureteric jet, detrusor overactivity, and bladder wall thickening. Children with bilateral immature jets, signifying a greater degree of immaturity, also showed a higher detrusor pressure and markedly thickened bladder wall. 
The latter two features were associated with detrusor overactivity, another sign of immaturity [16-18,25].

How are the immature jets related to immature detrusor muscle? We postulated that, as the detrusor muscle contributed to part of the sphincteric function of the VUJ, both detrusor muscle and the VUJ might be subject to similar rates of maturation. If a subject had signs of immaturity of one structure, they were more prone to immaturity of the other structure. Not all enuretic children have signs of immaturity of either detrusor muscle or the VUJ. The etiology of enuresis in these patients with clinically "mature" detrusor and VUJ might not be related to bladder overactivity but other etiologies. This is, however, beyond the scope of discussion in this study.

Limitations of the study. One of the limitations of this study was that completely age- and sex-matched controls could not be obtained for comparison with the enuretic group. Although there was a difference in the mean age of the enuretic children (mean age, $8.71 \mathrm{y}$ ) and the normal children (mean age, $10.68 \mathrm{y}$ ), the age difference could not account for the difference in incidence of the immature ureteric wave form observed in this study, as our previous study showed that the ureteric jet wave form was mature after the age of $4 \mathrm{y} \mathrm{(21).}$ There were more boys recruited in the enuresis group (male to female ratios of (2.57 to 1$)$. However, this was an intrinsic factor of the clinical problem, as enuresis is more predominant in males. The sex ratio in this study was similar to other studies $(2,9,19)$. Furthermore, our previous studies showed that sex had no effect on the incidence of monophasic wave form (20).

Strengths of the study. In a urodynamic study, the accuracy of the measurement of maximal bladder volume, residual volume, and emptying efficiency relies heavily on the cooperation of the child to sustain a full bladder. The procedure is also more invasive. In this study, the measurement of ureteric jet pattern and bladder wall thickness is much easier to obtain, irrespective of bladder volume, and does not require catheterization. In our center, ultrasound technologists/ sonographers could acquire a reasonably accurate technique of performing the evaluation after a training period of around 1 mo. Therefore, the technique may feasibly be implemented in a busy clinical practice.

\section{CONCLUSION}

In conclusion, we have introduced a noninvasive technique for assessment of the monophasic ureteric jet pattern and the bladder wall thickness, which are potentially useful parameters to identify a subgroup of enuretic children who have immaturity of the VUJ function and bladder overactivity. This technique might also provide a more ready-to-assess tool to study the effect of pharmacological agents on both VUJ and detrusor function in enuresis children. The clinical application of this technique on treatment monitoring in enuretic children warrants further investigation.

\section{REFERENCES}

1. Yeung CK, Sreedhar B, Leung VY, Metreweli C 2004 Ultrasound bladder measurements in patients with primary nocturnal enuresis: a urodynamic and treatment outcome correlation. J Urol 171:2589-2594

2. Yeung CK 1997 Nocturnal enuresis in Hong Kong: different Chinese phenotypes. Scand J Urol Nephrol Suppl 183:17-21

3. Houts AC 1995 Behavioural treatment for enuresis. Scand J Urol Nephrol Suppl 173:83-87

4. Hunsballe JM, Rittig S, Djurhuus JC 1995 Sleep and arousal in adolescents and adults with nocturnal enuresis. Scand J Urol Nephrol Suppl 173:59-61

5. Hunsballe JM, Hansen TK, Ritting S, Nørgaard JP, Pederse EB, Djurhuus JC 1995 Polyuric and non-polyuric bedwetting- pathological differences in nocturnal enuresis. Scand J Urol Nephrol Suppl 173:77-79

6. Watanabe H, Kawauchi A 1999 Locus coeruleus function in enuresis. Scand J Urol Nephrol Suppl 202:14-17

7. Yeung CK, Chiu HN, Sit FK 1999 Sleep disturbance and bladder dysfunction in enuretic children with treatment failure: fact or fiction? Scand J Urol Nephrol Suppl 202:20-23

8. Nørgaard JP, Pederse EB, Djurhuus JC 1985 Diurnal anti-diuretic-hormone levels in enuretics. J Urol 134:1029-1031

9. Kirk J, Rasmussen PE, Ritting S, Djurhuus JC 1996 Provoked enuresis-like episodes in healthy children 7 to 12 years old. J Urol 156:210-213

10. Aikawa T, Kasahara T, Uchiyama M 1998 The arginine-vasopressin secretion profile of children with primary nocturnal enuresis. Eur Urol 33:41-44

11. Chiozza ML, Plebani M, Scaccianoce C, Biraghi M, Zacchello G 1998 Evaluation of antidiuretic hormone before and after long-tern treatment with desmopressin in a group of enuretic children. Br J Urol 81:53-55

12. van Gool JD, Nieuwenhuis E, ten Doeschate, IO Messer TP, de Jong TP 1999 Subtypes in monosymptomatic nocturnal enuresis II. Scand J Urol Nephrol Suppl 202:8-11

13. Torrens MJ, Collins CD 1975 The urodynamic assessment of adult enuresis. Br J Urol 47:433-440

14. Jørgensen TM, Djurhuus JC, Schrøder HD 1982 Idiopathic detrusor sphincter dyssynergia in neurologically normal patients with voiding abnormalities. Eur Urol 8:107-110

15. Jørgensen TM, Mortensen J, Nielsen K, Djurhuus JC 1984 Pathogenetic factors in vesico-ureteral reflux. Scand J Urol Nephrol 18:43-48

16. Yeung CK 1995 The normal infant bladder. Scand J Urol Nephrol Suppl 173:19-23

17. Yeung CK, Godley ML, Duffy PG, Ransley PG 1995 Natural filling cystometry in infants and children. Br J Urol 75:531-537

18. Yeung CK, Godley ML, Ho CK, Ransley PG, Duffy PG, Chen CN, Li AK 1995 Some new insights into bladder function in infancy. Br J Urol 76:235-240

19. vanGool JD 1999 Conservative management in children.. In: Abrams P, Khoury S, Wein A (eds) Incontinence: 1st International Consultation on Incontinence-June 28-July 1, 1998-Monaco, Health Publication Ltd, Plymouth, pp 489-501

20. Leung VY, Metreweli C, Yeung CK 2002 The ureteric jet Doppler waveform as an indicator of vesicoureteric sphincter function in adults and children. An observational study. Ultrasound Med Biol 28:865-872

21. Leung VY, Metreweli C, Yeung CK 2002 Immature ureteric jet Doppler patterns and urinary tract infection and vesico-ureteric reflux in children. Ultrasound Med Biol 28:873-878

22. Jequier S, Rousseau O 1987 Sonographic measurements of the normal bladder wall in children. AJR Am J Roentgenol 149:563-566

23. Yeung CK 1998 Continuous real-time ambulatory urodynamic monitoring in infants and young children using infrared telemetry. Br J Urol 81 Suppl 3:76-80

24. Nordling J 1990 Functional assessment of the bladder. Ciba Found Symp 151:139 155

25. Holmdahl G 1997 Normal bladder development and function. Scand J Urol Nephrol Suppl 188:14-15

26. Jørgensen TM, Djurhuus JC, Jørgensen HS, Sørensen SS 1983 Experimental bladder hyperreflexia in pigs. Urol Res 11:239-240

27. Wyndaele JJ 1992 La sensation du bas appareil urinaire est-elle différente chez des patients ayant une instabilitévésicate. [Is the lower urinary tract sensation different in patient with bladder instability?]. Prog Urol 2:220-225

28. Diokno AC, Koff SA, Bender LF 1974 Periuretheral striated muscle activity in neurogenic bladder dysfunction. J Urol 112:743-749

29. Watanabe H, Azuma Y 1989 A proposal for a classification system of enuresis based on overnight simultaneous monitoring of electroencephalography and cystometry. Sleep 12:257-264

30. Cisternino A, Passerini-Glazel G 1995 Bladder dysfunction in children. Scand J Urol Nephrol Suppl 173:25-29

31. Tibballs JM, De Bruyn R 1996 Primary vesicoureteric reflux- how useful is postnatal ultrasound? Arch Dis Child 75:444-447

32. Tanagho EA, Meyers FH, Smith DR 1968 The trigone: anatomical and physiological considerations. 1 In relation to the ureterovesical junction. J Urol 100:623-632

33. Tanagho EA, Lue TF 2000 Neuropathic bladder disorders. In: Tanagho EA, McAniach JW (eds) Smith's General Urology. McGraw Hill, New York pp 498-515

34. O'Donnell B, O'Connor TP 1971 Bladder function in infants and children. Br J Urol 43:25-27 